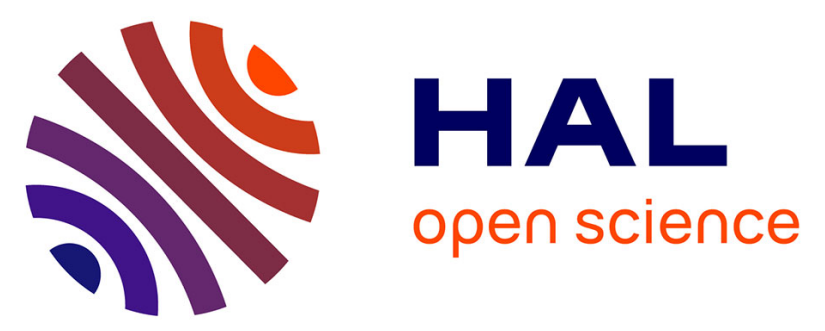

\title{
A novel deep-UV polymer for integrated photonics: from waveguides structures to taper-waveguides coupled to cascade of multistage resonators used as thermal sensors
}

Rigoberto Castro-Beltran, David Pluchon, Daphné Duval, Marion Specht, N. Huby, Hervé Lhermite, Goulc'Hen Loas, Lionel Camberlein, Etienne Gaviot, Bruno Bêche

\section{To cite this version:}

Rigoberto Castro-Beltran, David Pluchon, Daphné Duval, Marion Specht, N. Huby, et al.. A novel deep-UV polymer for integrated photonics: from waveguides structures to taper-waveguides coupled to cascade of multistage resonators used as thermal sensors. Latin America Optics and Photonics Conference (LAOP 2014), 2014, Cancun, Mexico. 10.1364/LAOP.2014.LM4A.44 . hal-01452368

\author{
HAL Id: hal-01452368 \\ https://hal.science/hal-01452368
}

Submitted on 1 Feb 2017

HAL is a multi-disciplinary open access archive for the deposit and dissemination of scientific research documents, whether they are published or not. The documents may come from teaching and research institutions in France or abroad, or from public or private research centers.
L'archive ouverte pluridisciplinaire HAL, est destinée au dépôt et à la diffusion de documents scientifiques de niveau recherche, publiés ou non, émanant des établissements d'enseignement et de recherche français ou étrangers, des laboratoires publics ou privés. 


\section{A novel deep-UV polymer for integrated photonics: From waveguides structures to taper- waveguides coupled to cascade of...}

Conference Paper $\cdot$ November 2014

DOI: 10.1364/LAOP.2014.LM4A.44

CITATIONS

0

10 authors, including:
READS

24

\section{Daphné Duval}

Catalan Institute of Nanoscience and Nanotech.. 53 PUBLICATIONS 137 CITATIONS

SEE PROFILE

E. Gaviot

Université du Maine

105 PUBLICATIONS 510 CITATIONS

SEE PROFILE

\section{Lionel Camberlein}

Université du Maine

49 PUBLICATIONS 130 CITATIONS

SEE PROFILE

Bruno Bêche

Université de Rennes 1

143 PUBLICATIONS 608 CITATIONS

SEE PROFILE

Some of the authors of this publication are also working on these related projects:

A novel deep-UV polymer for integrated photonics: From waveguides structures to taper-waveguides coupled to cascade of multistage resonators used as thermal sensors View project

Project Nonlinear plasmonics. Microresonators for Kerr combs View project 


\title{
A novel deep-UV polymer for integrated photonics: from waveguides structures to taper-waveguides coupled to cascade of multistage resonators used as thermal sensors
}

\author{
R. Castro-Beltran ${ }^{1,2}$, N. Huby ${ }^{1}$, D. Pluchon ${ }^{1}$, D. Duval ${ }^{1}$, M. Specht ${ }^{1}$, H. Lhermite ${ }^{3}$, G Loas $^{1}$, L Camberlein $^{4}$, E \\ Gaviot $^{4}$ and B. Bêche ${ }^{1}$ \\ ${ }^{1}$ Université de Rennes 1, IPR CNRS 6251, Rennes, 35042, France \\ ${ }^{2}$ Centro de Investigaciones en Óptica, Loma del Bosque 115, 37150 León, Gto., México. \\ ${ }^{3}$ Université de Rennes 1, IETR CNRS 6164, Rennes, 35042, France \\ ${ }^{4}$ LAUM UMR CNRS 6613, Université du Maine, Avenue Olivier Messiaen, 72085 Le Mans Cedex 9, \\ email: cbrigoberto@cio.mx, nolwenn.huby@univ-rennes1.fr and bruno.beche@univ-rennes1.fr
}

\begin{abstract}
An overview of current research on integrated photonics based on the new UV210 photoresist is given. We report the overall design, fabrication and characterization of waveguides structures, multistage microresonators and their potential as thermal sensors.
\end{abstract}

OCIS codes: (130.0130) General; (130.6010)

\section{Introduction}

Over the last decade the development of new photonic devices (PD) in the submicrometer range through simple and low cost has been extremely important for biological and telecom applications [1]. Moreover, the ability to develop new photonic devices through simple, low cost and mass production fabrication steps based on new organic materials allowing the sub-wavelength resolution is substantial. Nevertheless, submicrometer systems require critical procedures to be fabricated [2]. Recently, DUV lithography system allows a reduction in the optical lithographic wavelength by changing the presentation of the filters, and with this a better resolution on the wavelength patterns can be achieved [3]. In order to fabricate various photonic devices such as sub-wavelength waveguides and serial families of micro-resonators (MRs), we have developed deep ultraviolet (DUV) lithography processes using the chemically amplified UV210 photoresist. The capacity of new photoresist to support serial of photonic structures which are mainly constituted by tapered waveguides and resonant shapes, e.g., MR, demonstrated the capability of this to contribute in the trend of photonic miniaturization and mass production. The overall optical characterization and responses such as evolution of the UV210 optical index function on the irradiation dose, propagation losses measurements, optical resonances of the MRs-devices, quality factors and strong extinction rate on the resonance of family filters and finally the thermally tunable response, showing the high capability of this PD for technological application, will be presented as the most outstanding results of this work.

\section{Presentation, fabrication and visualization of the devices under test}

Handling all the adequate technological steps, involving DUV lithography processes and control of the index value of the polymer by irradiation, we demonstrate that such a polymer, allowing $300 \mathrm{~nm}$-well-defined patterns, is totally appropriate for the realization of sundry photonics structures: sub-wavelength tapers waveguides [4] and cascade of multiple optical micro-resonators shaped as disk, ring, stadium and racetrack $[5,6]$.
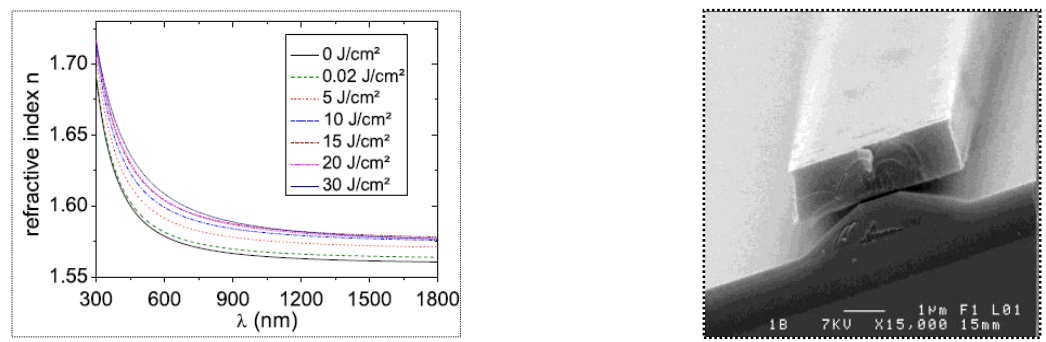

Fig. 1. Ellipsometric dispersion curves ascribed to the optical refractive index values of UV210 thin films with different deep-UV irradiation doses; scanning electron microscopy (SEM) image of a UV210 pedestal rib-waveguide. 
Measurements of the optical losses, with the cut-back method, realized over the single-mode $\mathrm{TE}_{00}$ and $\mathrm{TM}_{00}$ rib waveguides, are $\alpha \mathrm{TE}=3.4 \pm 0.4 \mathrm{dBcm}-1$ and $\alpha \mathrm{TM}=6.2 \pm 0.5 \mathrm{dBcm}-1$ regarding both polarizations. These results prove that this photo-resist is a promising material for the realization of sub-wavelength structures in integrated optics with applications in telecom and sensor technologies, see Fig.1.

For signal processing applications and label free biochemical sensor, MRs represent an emerging technology that has been under intensive investigation lately. MRs have proven to be one of the most versatile designs for desirable filter transfer functions, as evidenced by their widespread use in electronics besides, the detection mechanism relies on the sensitivity of the optical mode guided inside the core of the MR to its surroundings via the evanescent field, magnified by the long effective interaction length obtained near resonance[6,7]. Nevertheless, variations and changes in the fabrication and environment difficult the wavelength manipulation. Recently, cascade of multiple MR devices have found promising functionality as a reactive optical element by making the resonance response steeper and with this, enhance the optical transmission features such as the finesse and the quality factor (Q) [8].

Figure 2 shows thee global information, fabrication procedure, geometrical parameters and the accuracy and quality of the lithography procedures for single Ring and RaceTrack MR. Due to the features and presentations on all the design of the devices under test, e.g., with multistage (Single, Double and Triple), with Ring and RaceTrack shapes, with radius of $\mathrm{R}=25 \mu \mathrm{m}$ (Small) and $\mathrm{R}=50 \mu \mathrm{m}$ (Large), it is practical to refer to them, e.g., in the case of triple devices, as TSR, TLR, i.e., for instance TLR: Triple Large Ring. The inset in the Fig. 2 (a) represents the global fabrication procedure by DUV lithography. Fig. 2 (b) and Fig. 2 (c) shows the tilted top-view of the TLRT confirming constancy on the properties of the cascade of MR.
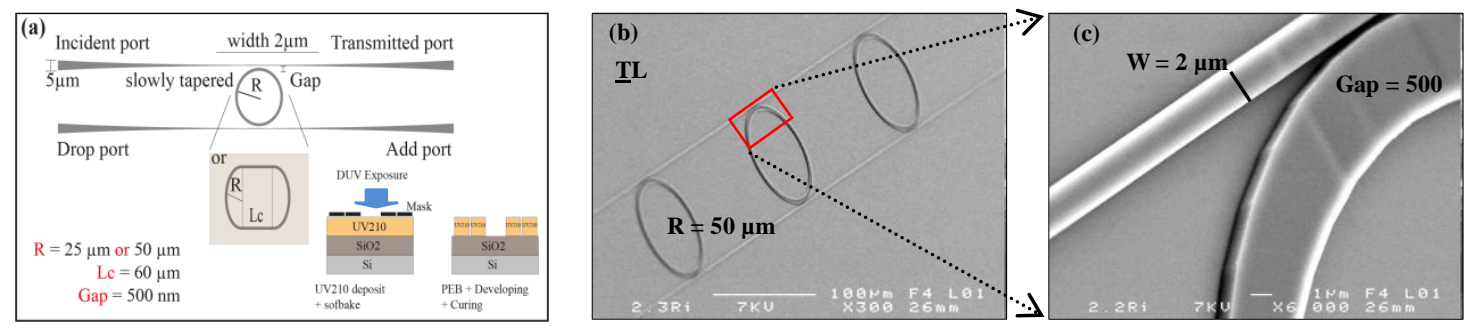

Fig.2. (a) Representation and details of single microRing and single microRaceTrack. (b) SEM images of the TLR device and (c) the fabrication quality on the coupling zone of one of its MR.

\section{Optical characterization}

In order to analyze further the role of geometry and multistage as well as their behavior to different light sources, Fig. 3 summarizes the evolutions of the Q-values for the devices under test.
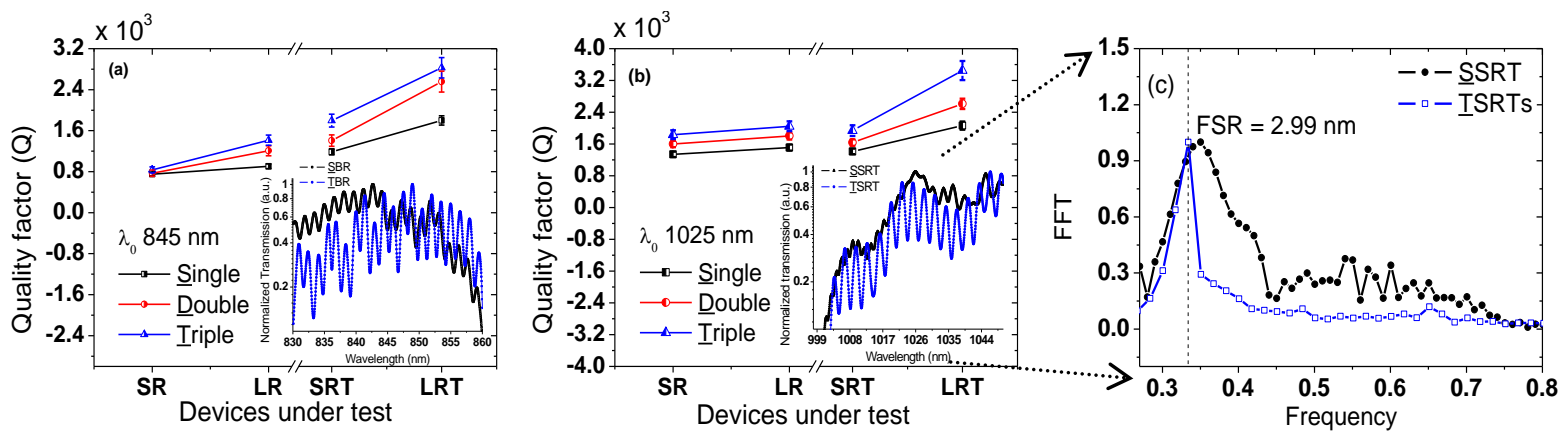

Fig. 3. Q-factor values as a function of the multistage configuration by using two broadband sources centered at (a) $845 \mathrm{~nm}$, (b) $1025 \mathrm{~nm}$ and (c) modal filter behavior. The insets in both show comparison in the transmissions between Single and cascade of Triple MR.

The graphs present a clear evolution in the enhancement of their optical properties as the number of loops and dimensions in the devices increases. Referring to the inset in Fig.3 (b) and Fig. 3 (c), multiple MRs can act as modal filters. 


\section{Thermal tuning}

For electronics capability and biological stability, thermal tuning and temperature control are mandatory in submicrometer PD and cascaded of microcavities are demonstrated to have advantages on it. The Fig. 4 presents the thermal tuning response of TLRT under two different cladding conditions by using a heater tip (alloy $\mathrm{NiCr}$ ) on top of the devices. The experimental average linear resonance shift obtained was equal to $0.19 \pm 0.018 \mathrm{~nm} /{ }^{\circ} \mathrm{C}$.
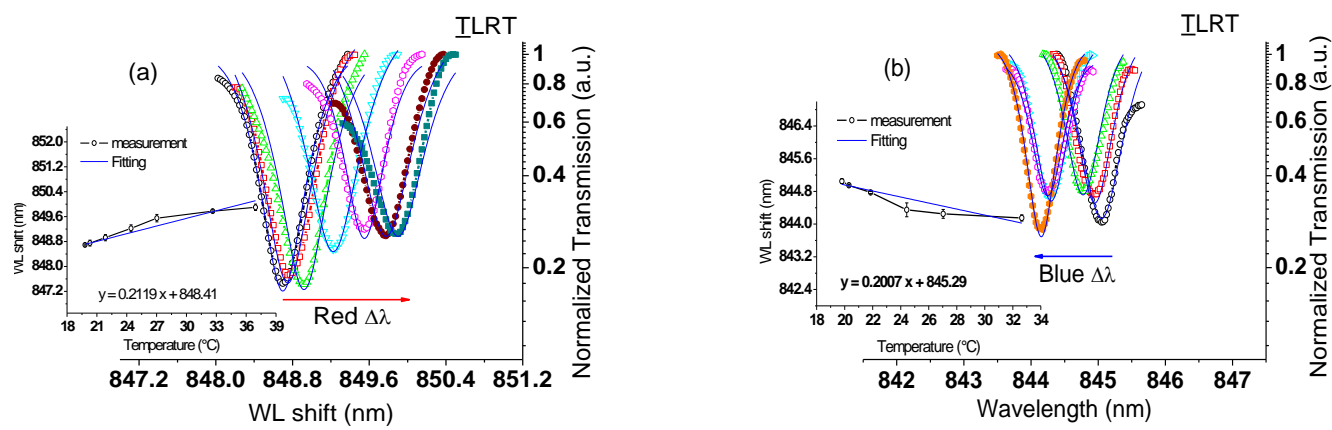

Fig. 4. Thermal shift of the resonance peak as a function of input temperature under different claddings: (a) air and (b) distilled water.

\section{Conclusion}

The high capacity of the chemically amplified UV210 polymer to develop various families of integrated components such as sub-wavelength optical elements and waveguides, tapered waveguides and cascade of MRs with different geometries and dimensions is highlighted in this work. The high quality and reproducible of the fabrication process by DUV lithography has been validated by Nomarsky microscopy, SEM images and totally confirmed by microbeam profiles. According to these evidences and complete optical characterization, all these designs and devices are markedly suitable for telecommunication and metrology applications. The obtained optothermal response was $<200 \mathrm{pm} /{ }^{\circ} \mathrm{C}$. Furthermore, the tunability accuracy has been confirmed by changing the top cladding of the devices from air to distilled water, leading to respectively a red and blue shift on the evolution of the resonance transmission.

\section{References}

1] W. Bogaerts, et al, "Silicon microring resonators", Laser Photonics Rev. 6, 47-73 (2012).

[2] L. Jay Guo, "Nanoimprint Lithography: Methods and Material Requirements", Advance Materials 19, 495-513 (2007).

[3] P. B. Sahoo, et al, "Progress in deep-UV photoresist”, Bulletin of Materials Science 25, 553-556 (2002).

[4] D. Duval, H. Lhermite, C. Godet, N. Huby, B. Bêche, Institute of Physics Publishing - J. Opt. A: Pure Appl. 12, 055501-055507 (2010).

[5] D. Pluchon, N. Huby, H. Lhermite, D. Duval, B. Bêche, Institute of Physics Publishing I - J. Micromech. Microeng., 22, 085016-085024 (2012).

[6] R. Castro Beltran, N. Huby, G. Loas, H. Lhermite, D. Pluchon, B. Bêche, Institute of Physics Publishing - J. Micromech. Microeng. submitted, (2014).

[7] Delezoide C, Salsac M, Lautru J, Leh H, Nogues C, Zyss J, Buckle M, Ledoux R I and Thanh N C, IEEE Photon. Tech. Lett. 24 1-3 (2012)

[8] B. D. Timotijevic, et al, "Multi-stage racetrack resonator filters in silicon-on insulator", J. Opt. A: Pure and applied optics 8, S473-S476 (2006). 